\title{
Teaching Innovation under the Concept of Learning Competition
}

\author{
Zhenchang Liu, 2, a, Jingying Cao 2, b , Youyikang Wang ${ }^{3, \mathrm{c}}$ and Bing Wang, 1, d \\ ${ }^{1}$ School of Electrical and Information Engineering, Tianjin University, Tianjin 300072, China; \\ ${ }^{2}$ Tianjin Electronic Information College, Tianjin 300350, China; \\ ${ }^{3}$ Tianjin Vocational College of Mechanics and Electricity, Tianjin 300350, China.
}

aLiuzhenchang@126.com, bJoyce54yy@163.com, '649908401@qq.com, dBingwang@tju.edu.cn

\begin{abstract}
At present, in view of the disconnection between university personnel training and social needs, it is difficult to realize the integration of production and education, and to cultivate innovative high-quality technical and skilled talents. This article wants to explore the training mode of learning competition, relying on professional training to expand and cooperate with enterprises. The studio will be built to form a long-term mechanism for the selection, preparation, training and promotion of the skills competition. Finally, the development of skill competition, practical training, teacher research, and student innovation will be explored. The new teaching model will lay the foundation for further exploring the new system of talents in the electrical automation profession to cultivate innovative talents and social services.
\end{abstract}

Keywords: Learning competition, Resource transformation, Comprehensive practice, Curriculum system.

\section{Introduction}

Based on the existing electric talent training program of higher vocational colleges, new research ideas are proposed. According to the current teaching, the curriculum sequence is adjusted, and the application of PLC technology and the application ability of single-chip microcomputer are taken as the main line, the actual ability training is strengthened, and the practical ability and programming ability are increased. Increase the PLC programming learning time. Master the use of two or more small and medium-sized PLC. Introduce project concepts and set up project teams to simulate various problems encountered in actual projects. Establish a collaborative studio training model with the enterprise, and introduce the actual project into the teaching [1]. The teacher extracts the content of the decomposition project and transforms it into the teaching knowledge point and skill point.

The application platform of this paper includes electrical technology, electrical measurement technology, electrical control technology, electrical engineering drawing, motor drive and speed control, programmable controller application technology, touch screen configuration control technology, industrial network technology, sensor technology, etc. Knowledge and skill requirements. It can design, install and debug integrated electrical control system of process control system, sequence control system, monitoring system and network control system, including design and preparation of control program, operation and debugging of overall control system, configuration monitoring screen and upper and lower position machine Communication and design between[2]. The above content is both professional content and the test site of the competition. Under the comprehensive mode of exploring the academic competition, the starting point and the foothold of the integrated training course of electrical automation professional form the corresponding curriculum standards. The integrated teaching system are shown in figure 1. 


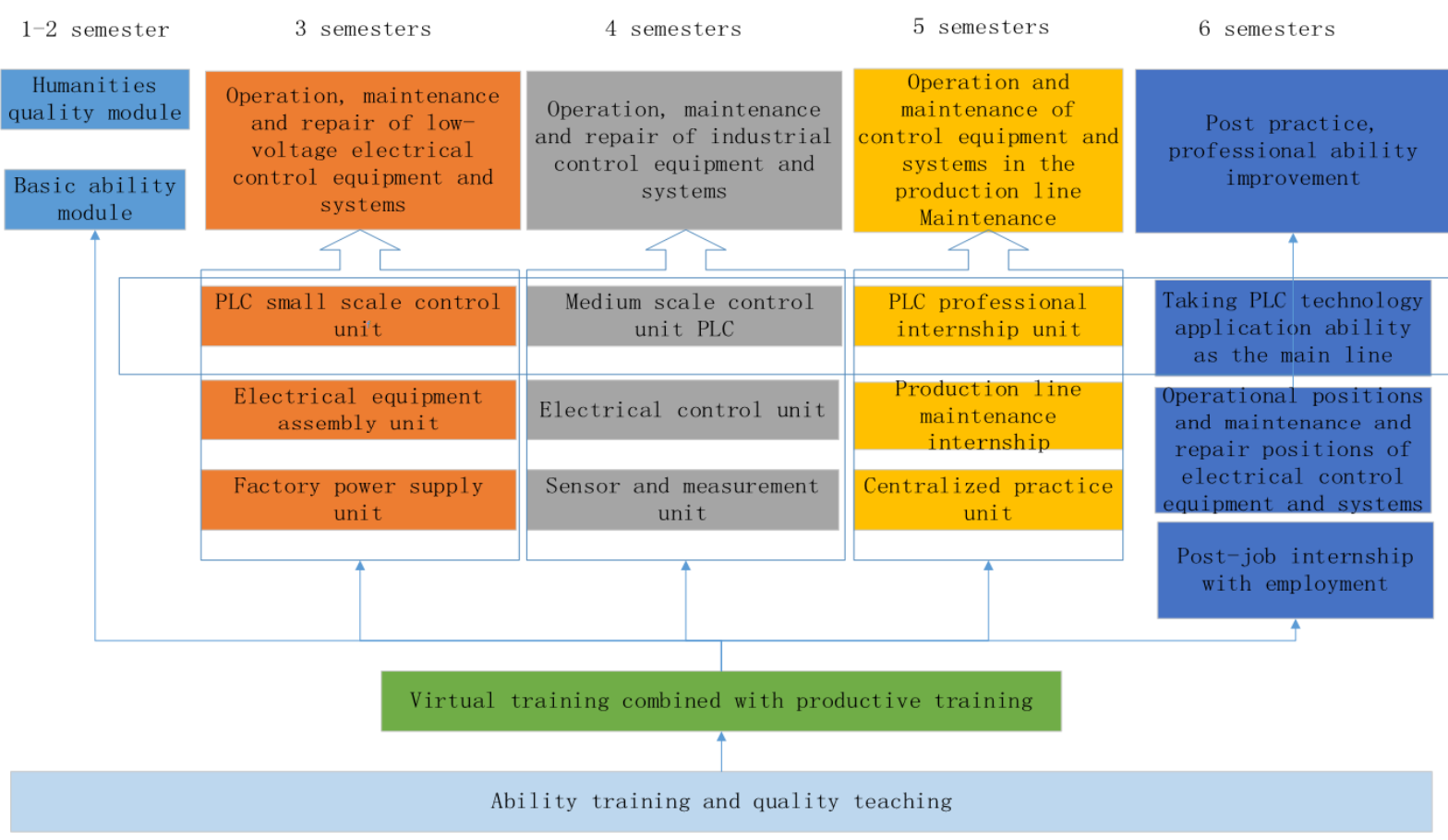

Fig 1. Integrated teaching system

\section{Curriculum Development}

\subsection{Research Purposes}

The training platform of YL-158GA1 is based on the actual work task. The technical content involves high-level electrical automation technology, electrical equipment application and maintenance, mechatronics technology, low-voltage electrical appliance manufacturing and application, power supply technology, PLC technology. Teaching content specified by related majors such as electrical measurement and control technology and industrial network technology. It analyzes the current teaching, the shortcomings in the preparation for the competition, and perfects the mode of integration of the academic competition, which is more suitable for the needs of the new curriculum construction system, and is more suitable for the future career development of students, so that students can better connect with practical applications [3].

\subsection{Research Perspective}

The modern electrical control system integrates PLC (programmable controller), HMI (human machine interface), motion control technology, industrial network technology and modern industrial production [4]. It covers the core content of high-level, applied undergraduate electromechanical and automation related majors, fully embodies the modern industrial production and management concept of integration of learning, electromechanical integration, management and control, and integration of high-end skills for intelligent equipment. Provide a new carrier, contribute to China's goal of achieving China's manufacturing 2025.Pay attention to the training of "complex" skills, Strengthen and build a diverse talent training model.

Taking the concept of learning to play as the carrier, condensing the teachers inside and outside the school to form a scientific and technical team with collaborative spirit [5]. Establish research and exploration of the electrical manufacturing training course system, and develop a system for electrical professional construction that is more suitable for higher vocational education, better adapt to the future development of intelligent manufacturing and the needs of society [6]. The training platform integration technology are shown in figure 2. 


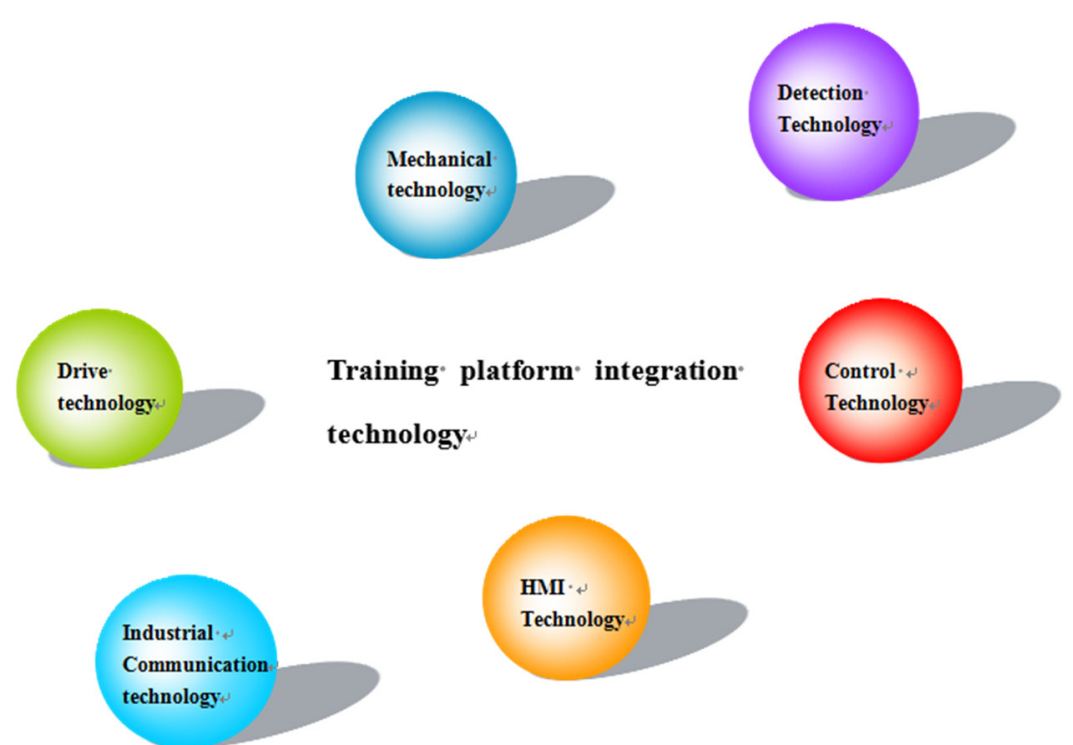

Fig 2. Training platform integration technology

\section{Innovation}

(1)According to the concept of the school competition, the knowledge points of the training platform are decomposed.

According to the concept of learning and learning, the knowledge points are decomposed into different levels of requirements, so that students have corresponding practical projects in the threeyear learning process, and can distinguish the different requirements of teaching and preparation.

(2)Train students to use the platform to enhance their independent learning and innovation capabilities.

According to the hardware and software situation of the training platform, students will develop their own ability to develop new projects and new technologies. Improve students' ability to innovate and create, for example, lead students to improve current communication and control methods.

(3)Form a management system that trains students and trains student systems.

Establish a good, step-by-step training of students, manage the student system, and better select the skills contest players, the system should be transplantable, reproducible, and facilitate the entire research team to be constructive.

\section{Course Import}

During the course introduction, we started from the actual engineering case, as shown in figure 3, the left half of the figure is a schematic diagram of the actual engineering. Its realization function is to collect the sensors, running status, scanner information and so on distributed in the field equipment through PLC, upload the data to the MES through the network switch, compare the information, record and confirm the production information of each product to greatly improve the accuracy of the information, insure the quality of the product and have traceability [7]. The right part of the picture is the introduction of S7 - 200 PLC communication methods in our course. From the picture, we can see that S7 - 200 PLC includes free communication, PPI and other communication methods. The introduction of such courses greatly improves students' desire and enthusiasm for new knowledge to really let them know what they have learned is useful. 


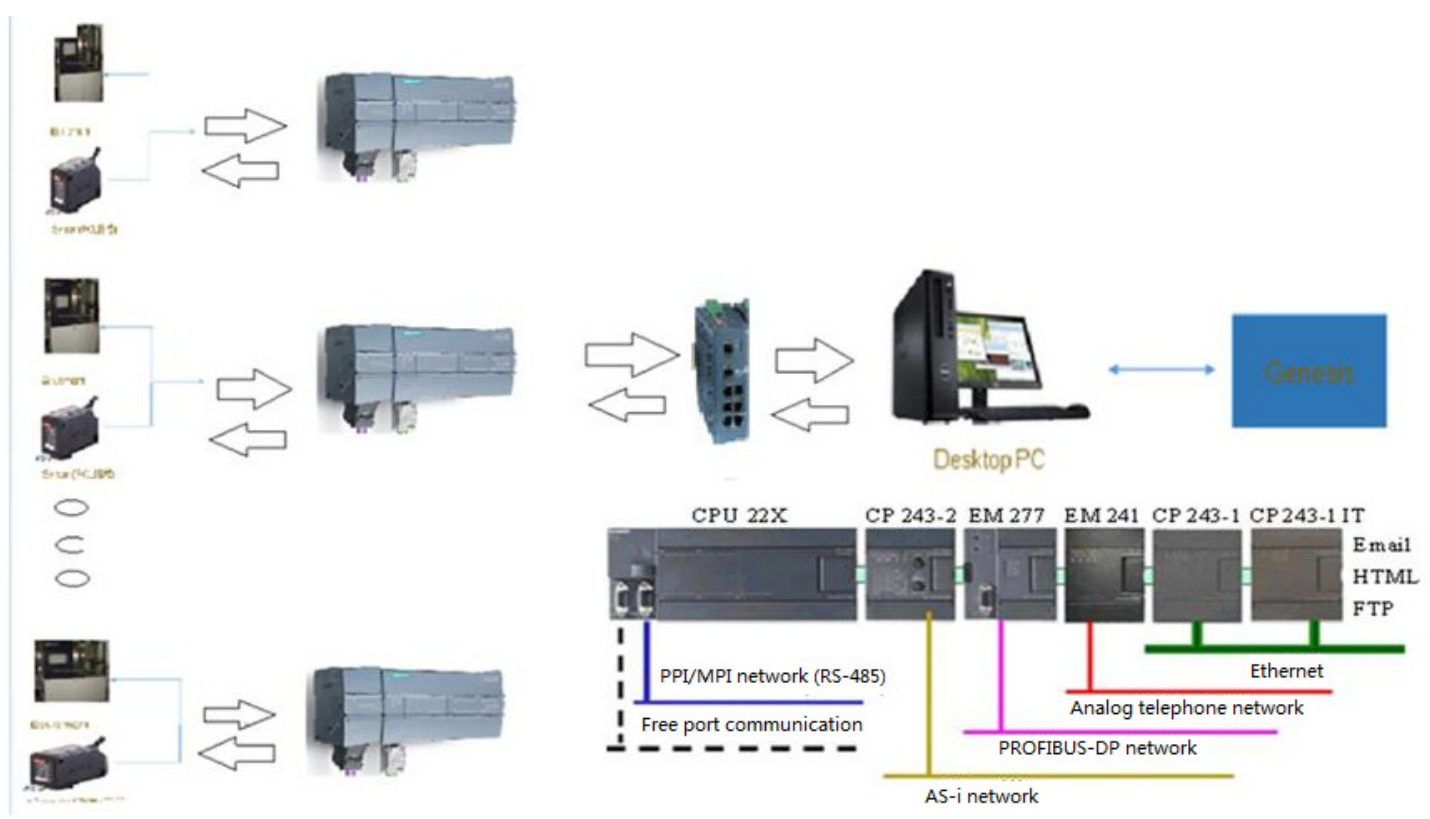

Fig 3. Schematic diagram of course import

\section{Theoretical Significance and Application Value}

At present, most of the training platforms are service skill contests. However, in actual operation, it is very difficult to select the contestants. The reason for the analysis is the current teaching content, the curriculum is not fully adapted to the technical requirements of the Skills Competition. Students start from training and can complete the project independently for a long period of time. Therefore, based on the above reasons, we want to build a new training platform system based on the concept of learning competition, propose a new teaching and training program, and decompose the project into three years of study [8]. For students who are suitable for the first-grade entry level, there are those who are suitable for the second-grade basic level, and those who are suitable for the third-grade comprehensive level. For the competition, there are those who can adapt to the selection of the players, and those who are suitable for participating in the competition [9].

(1)Learning: entry level, basic level, comprehensive level.

The above three levels are mainly for the knowledge points of the professional skills of all electrical automation students, so that students can learn theoretical knowledge and practice better.

(2)Competition: entering the class, the actual level.

The above two levels are mainly used to select the players who are more suitable for the competition. The teachers analyze the assessment points of the annual competition questions and predict the future development direction of the technology.

(3)Propose an improvement plan, keep up with new developments in technology, and new applications.

For example, the servo motor of the training platform can communicate and communicate with the PLC by means of communication. Another example is the interaction of two or three training platform data, simulating the effect of collaborative work of different workstations, improving the efficiency of platform use, and stimulating students' enthusiasm for innovation [10]. Another example is to explore a new method for controlling stepper motors using a module that uses analog tonal pulse signals.

\section{Research Results}

At present, the research and teaching effect has won the second prize in Changzhou in 2018, and won the first prize in Tianjin in 2017, the third prize in the 2016 national competition, and the second prize in the 2015 Tianjin competition. In the training platform assessment points, skills points, there 
is a relatively full understanding, and there are relevant technical reserves and ideas for future technological development. However, there are some deficiencies and areas for improvement in training management students, such as how to supervise students in the process of long-term training of students; to cultivate students' ability to learn independently; to enable students to learn and improve in software and hardware, respectively, to meet the requirements of the competition ; The connection between teaching and competition and employment; therefore, it is necessary to improve management in more aspects, and use the concept of learning to improve the practical teaching effect of electrical automation.

This work is supported by Tianjin Higher Vocational and Technical Education Research Association NO.XVII4105 and Tianjin education science "13th five-year plan" NO.VEYP5044.

\section{References}

[1]. Morag Paxton. Students' interim literacies as a dynamic resource for teaching and transformation [J]. Southern African Linguistics \& Applied Language Studies, 2007, 25(1):45-55.

[2]. Wang F. Research on the Transformation of Teaching Situation in Document Retrieval Course under the Revolution of Resource Organization Situation [J]. Information Studies Theory \& Application, 2016.

[3]. Zhu C M. Construct Ways and Means of Software Technique Specialty Teaching Resource Library in Higher Vocational Education by School and Enterprise Alliance [J]. Software, 2013.

[4]. Wang F. Research on the Transformation of Teaching Situation in Document Retrieval Course under the Revolution of Resource Organization Situation [J]. Information Studies Theory \& Application, 2016.

[5]. Ai-Goo J I. Study and Practice of a Comprehensive Experimental Teaching Mode [J]. Research \& Exploration in Laboratory, 2007.

[6]. Lin M H, Zhang J, Boa Z W. Improve the Mode of Teaching and Learning Based on Developing Subject Competitions [J]. Journal of Fujian Normal University, 2011.

[7]. Chen W, Cui S X. Prospects on implementation effect of learning competition and competitiondriven vocational English teaching [J]. Heilongjiang Science, 2016.

[8]. Raman S, Hansen J H L, Raman S, et al. Curriculum Learning Based Approaches for Noise Robust Speaker Recognition [J]. IEEE/ACM Transactions on Audio Speech \& Language Processing, 2018, PP (99):1-1.

[9]. Yang L, Ye W, Yang Y. The Construction of Humanistic Curriculum System for Innovation and Entrepreneurship Education in Vocational Colleges [J]. Journal of Heike University, 2018.

[10]. Xu Q, Tan P F, Cain S H. Exploration and Construction of Curriculum System of General Practice [J]. Journal of Jiangxi University of Traditional Chinese Medicine, 2018. 